Article

\title{
Damage Characterisation of Nanointerleaved Woven CFRP Under Fatigue Loading
}

\author{
Sakineh Fotouhi ${ }^{1}$, Mohamad Fotouhi ${ }^{{ }^{*}}$, Milad Saeedifar ${ }^{3}$, Hamed Saghafi ${ }^{4}$, Cristiano Fragassa ${ }^{5}$, \\ Giangiacomo Minak ${ }^{5}$ \\ 1 Mechanical Engineering Department; University of Tabriz; Tabriz; Iran; s.fotouhi@tabrizu.ac.ir \\ 2 Department of Design and Mathematics; The University of the West of England; Bristol BS16 1QY; UK; \\ mohammad.fotouhi@uwe.ac.uk \\ * Correspondence: mohammad.fotouhi@uwe.ac.uk; Tel.: +447407266470 \\ ${ }^{3}$ Non-destructive Testing Lab; Department of Mechanical Engineering; Amirkabir University of Technology; \\ 424 Hafez Ave, 15914, Tehran, Iran. \\ ${ }^{4}$ Department of Mechanical Engineering; Tafresh University, Tehran Road; 7961139518; Tafresh; Iran \\ ${ }^{5}$ Alma Mater Studiorum University of Bologna, Department of Industrial Engineering, Viale Risorgimento 2, \\ 40136 Bologna, Italy
}

\begin{abstract}
The use of high strength to weight ratio laminated composites is emerging in marine industry and applications as a very efficient solution for improving productivity. Nevertheless, delamination between the layers is a limiting factor for the wider application of laminated composites, as it reduces the stiffness and strengths of the structure. Interleaving nanofibrous mats between layers of composite laminates has been proved to be an effective method for improving composites delamination resistance. This paper aims to characterize the effect of interleaved nanofiber on mode I interlaminar properties and failure mechanisms when subjected to static and fatigue loadings. For this purpose, virgin and nanomodified woven laminates were subjected to Double Cantilever Beam (DCB) specimens. Static and fatigue tests were performed and the tests were monitored by acoustic emission technique. The mechanical results showed a $130 \%$ increase of delamination toughness for nanomodified specimens in the static loadings and more crack growth resistance in the fatigue loading. The AE results revealed that different type of failure mechanisms was the cause of these improvements for the modified specimens compared with the virgin ones.
\end{abstract}

Keywords: Fatigue; Delamination; Acoustic Emission; Failure Mechanisms; Composite Materials; Nanofibers, Marine Applications.

\section{Introduction}

The use of carbon fiber reinforced polymer (CFRP) composites has increased due to their high strength and stiffness properties combined with lightness. CFRP is one of the best options as a structural material in aerospace, automotive, and marine industries. CFRP laminated composites are usually produced by draping, stacking, and curing multiple sheets of prepregs together. CFRP offers excellent in-plane properties, but they suffer from delamination or crack-like damages between the ply interfaces, which are mostly the matrix-rich areas.

Different methods such as stitching of the laminas, matrix toughening, and three-dimensionalbraided fabrics have been investigated to prevent delamination [1-5]. Matrix-toughening has recently attracted a lot of attention at which delamination toughness increases by inserting interleaf layers of toughened materials between the layers during the laminate's fabrication process [6-8]. Recently, it was shown that PVDF nanofibers can increase mode I fracture toughness of epoxy-based laminates $[9,10]$ both in static and fatigue loading conditions, if they are treated in a specific situation such as appropriate curing temperature and nanofibrous mat thickness [11]. However, there is very limited information regarding the toughening and failure mechanisms of the PVDF-interleaved laminates in fatigue loading condition. 
This paper aims to investigate failure mechanisms caused during static and fatigue loadings of the nanofiber PVDF-interleaved laminates, using Acoustic Emission (AE) technique. AE signal is a spontaneous transient energy released by different damage sources such as matrix cracking, fiber breakage during the loading [12]. This technique was used to distinguish the failure modes in laminated composite materials and there was a promising applicability of this method [13-19]. Their results presented a capable applicability of AE parameters for classification of damage mechanisms in laminated composite materials.

In this paper, the mechanical data and the AE signals were used for investigation of the interlaminar properties and the relevant failure modes.

\section{Materials and Methods}

As illustrated in Figure 1, virgin and nano-interleaved DCB specimens were manufactured according to the ASTM D5528 [20] with dimensions of $140 \mathrm{~mm} \times 25 \mathrm{~mm}$. The stacking sequence was 14 plies of plain weave (PW) $220 \mathrm{gcm}$ carbon-epoxy prepreg (GG204P-IMP503Z), supplied by Impregnatex Composite Srl (Milan, Italy). Nylon 6,6 Zytel E53NC010, provided by DuPont, were used for producing nanofibers by means of electrospinning (see Figure 1a) as presented in [9]. 400 to $650 \mathrm{~nm}$ diameter nanofibers were randomly aligned in $40 \mu \mathrm{m}$ thick mats, with areal density of 18 $\mathrm{g} / \mathrm{m}^{2}$.

Laminates were $3.5 \pm 0.1 \mathrm{~mm}$ thick with no appreciable differences between configurations. Virgin and nano-interleaved specimens were cut from two rectangular panels: a $30 \mu \mathrm{m}$ thick PTFE film was inserted in the mid-interface during the lay-up to create an initial artificial crack which length ao was $45 \mathrm{~mm}$. Both panels were vacuum bag moulded following an optimized cure cycle in order to ensure the perfect penetration of the resin into the nanofibrous mat, before the hardening occurs. In particular the maximum temperature was $130^{\circ} \mathrm{C}$, below Nylon's melting temperature at $260^{\circ} \mathrm{C}$.

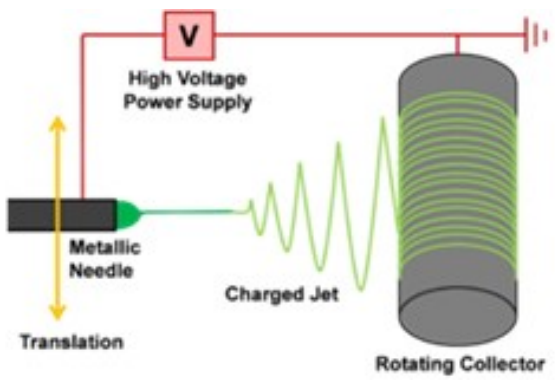

(a)

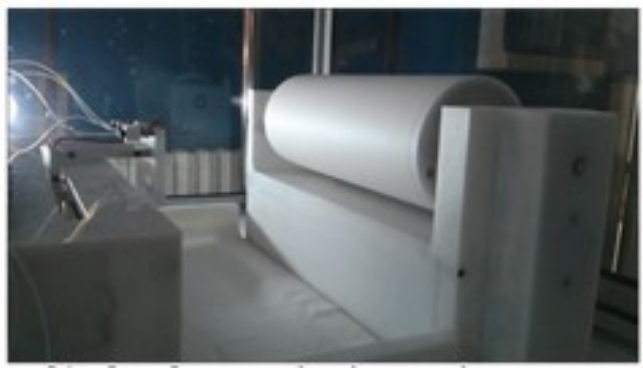

(b)

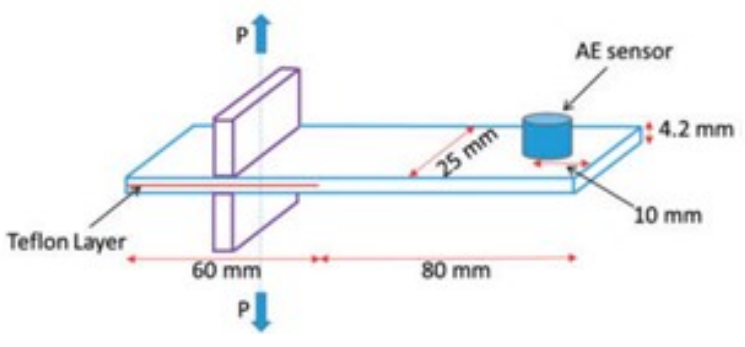

(c)

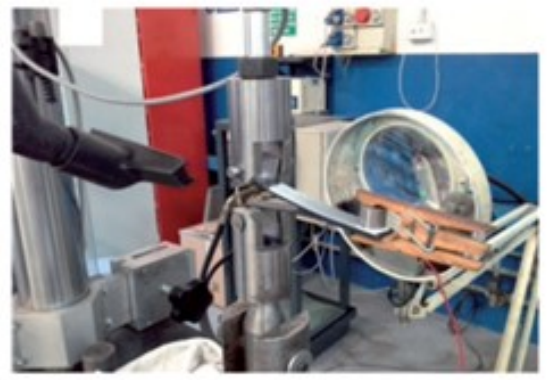

(d)

Figure 1: Electrospinning and testing equipment: (a) Schematic of the electrospinning process. (b) The electrospinning equipment. (c) Schematic of the DCB specimens. (d) DCB specimens and experimental setup.

The tests have been carried out in a servo-hydraulic press machine (Instron 8033) equipped with a $250 \mathrm{~N}$ load cell, under displacement control condition, at a constant crosshead speed of $3 \mathrm{~mm}=\mathrm{min}$. During the test, the load displacement curve was recorded and the crack propagation was visually determined by means of optical microscope. The Mode I energy release rate was determined according to the Modify Beam Theory (MBT), as suggested by the [21]. 
Samples for fatigue tests have been extracted from the same batch of those for static tests, therefore they had an identical dimensions and mechanical properties. Once manufactured, the specimens have been stressed until the crack started to propagate, in order to create a sharper and naturally developed crack within the specimens. The effective crack lengths were therefore $1 \mathrm{~mm}$ circa longer compared with the initial status. Fatigue tests were carried out following the guidelines provided in the ASTM D6115 [22] in the same Instron 8033 servo-hydraulic machine used for the static ones, equipped with a dedicated, in-house designed and manufactured $200 \mathrm{~N}$ load cell, under displacement control condition, at a load frequency of $3 \mathrm{~Hz}$, with fixed loading ratio $\mathrm{R}$ ( $\min =\max$ ) equal to 0.3. Load-displacement and crack length values (measured by a high-resolution camera) are used to calculate Gmax as proposed in [23].

AE waveforms were recorded using an AE data acquisition system called PCI-2 and the test sampling rate was $10 \mathrm{MHz}$. A schematic definition of the recorded waveforms and their features are shown in Figure 2. The utilized AE sensor was PAC R15, which is a broadband and single-crystal piezoelectric transducer. A 2/4/6-AST preamplifier with the gain selector of the $40 \mathrm{~dB}$ was used to enhance the detected signals and the threshold was set to be $35 \mathrm{~dB}$. Before the tests, a pencil lead break procedure was used to calibrate the data acquisition system. The AE software (AEWin) was used to extract AE signal features such as duration, rise time, amplitude, counts, energy, etc.

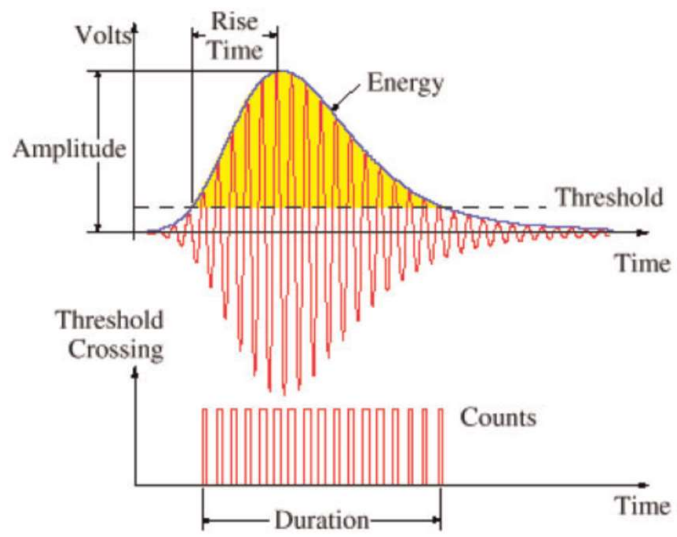

Figure 2. The definitions for acoustic-emission parameters [24].

\section{Results}

\subsection{Mechanical results}

Force-Displacement curves for the virgin and nano-interleaved samples are shown in Figure 3. For the fatigue samples, the energy release rates, which are calculated at the peak value of different number of cycles using Eq. (1), are reported in Figure 4. The results are clearly showing improvement in the fracture toughness for both static and fatigue loadings. 


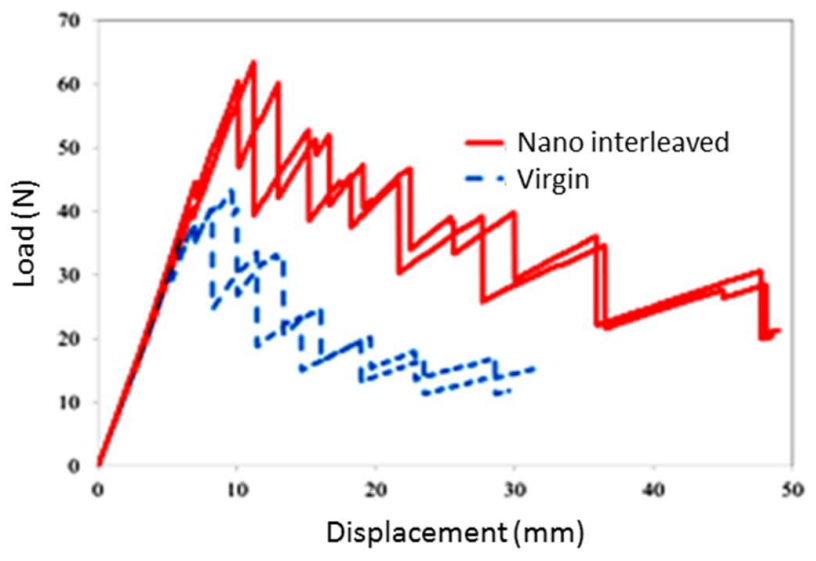

Figure 3. Load-Displacement curves of static tests.

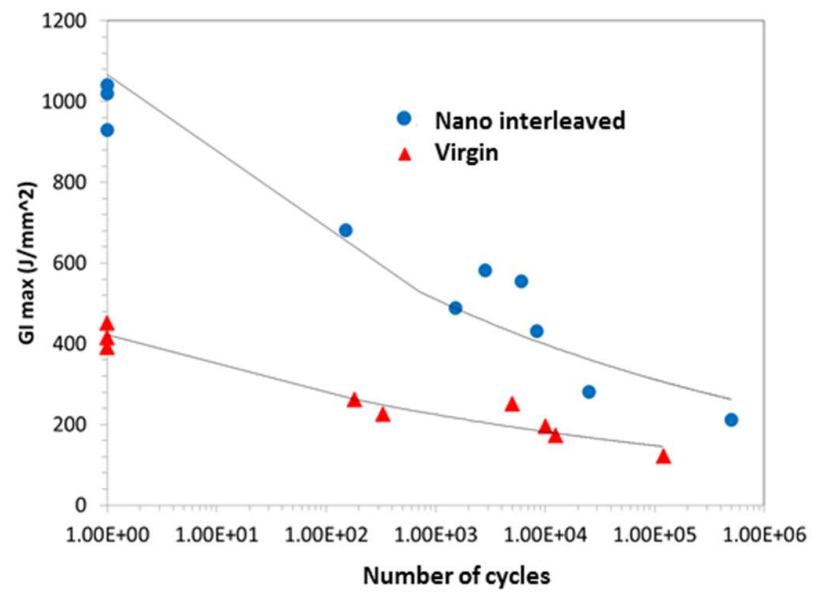

Figure 4. GImax-Na for the fatigue tests calculated based on ASTM D6115 [22].

\subsection{AE results}

Load-time and AE energy-time curves resulting from a virgin sample is illustrated in Figure 5 as a representative of the investigated samples behavior. A similar trend was observed for the nanointerleaved samples, where two different stages are observable regarding the mechanical and $\mathrm{AE}$ behavior:

1) Linear elastic region, before the propagation of delamination with no considerable damage in the specimens and therefore no change in mechanical and no AE signals with high energy content.

2) Crack initiation and propagation, where the stored strain energy in the specimens reaches the critical value and delamination initiates. Initiation of delamination is recognizable by the slope decrease in the load-time diagram (non-linearity point in ASTM5528 [21]). In the propagation stage, significant $\mathrm{AE}$ events appeared from a run-arrest extension of delamination and consequence appearance of the failure mechanisms. These AE signals were originated from different failure mechanisms during the propagation stage and can provide valuable information about the crack growth and arrest behaviors. The crack arresting stage is when the load increases and therefore stored strain energy accumulates in the specimen. When this strain energy reaches 
the critical strain energy, the crack propagates again and causes different types of failure mechanisms such as matrix cracking, fiber breakage, etc.

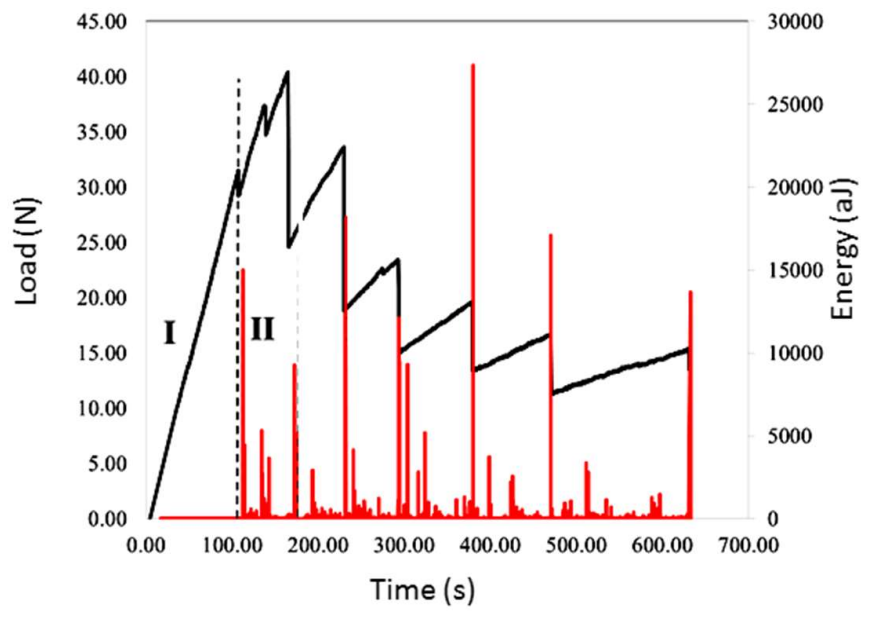

Figure 5. Load-time and AE energy time curves for the reference laminate.

The aim of this section is to identify the damage modes using the AE signals. A large body of literature can be found on $\mathrm{AE}$ amplitude or energy based classification of failure mechanisms in laminated composite materials [ 20 \& 25-30]. Their results revealed different amplitude and energy ranges for the failure modes observed. High ranges of amplitude, energy and frequency of AE signals were usually associated with fibre failure, middle ranges with delamination/debonding and low ranges with transverse/longitudinal matrix cracking. Three different classes of signals can be identified based on a previous study [31]: class (1) signals with 40-65 dB amplitude and 0-30 aJ energy related to noise, class (2) signals with 60-85 dB amplitude and 30-800 aJ energy related to debonding, class (3) signals with 75-100 dB amplitude and 800-65,000 aJ energy originating from carbon fibre failure. Figures 6 and 7 show the obtained AE signals classified based on the aforementioned criteria for the static and fatigue loadings, respectively. The AE events appeared in the virgin samples are higher than the nano-modified samples (see Figure 6.b.). Comparing the damage mechanisms in the fatigue loading in Figure 7, the initial damage in the virgin sample is matrix cracking and debonding, whereas the damage in the nano-interleaved sample started with a higher amplitude that is associated with fibre breakage. 

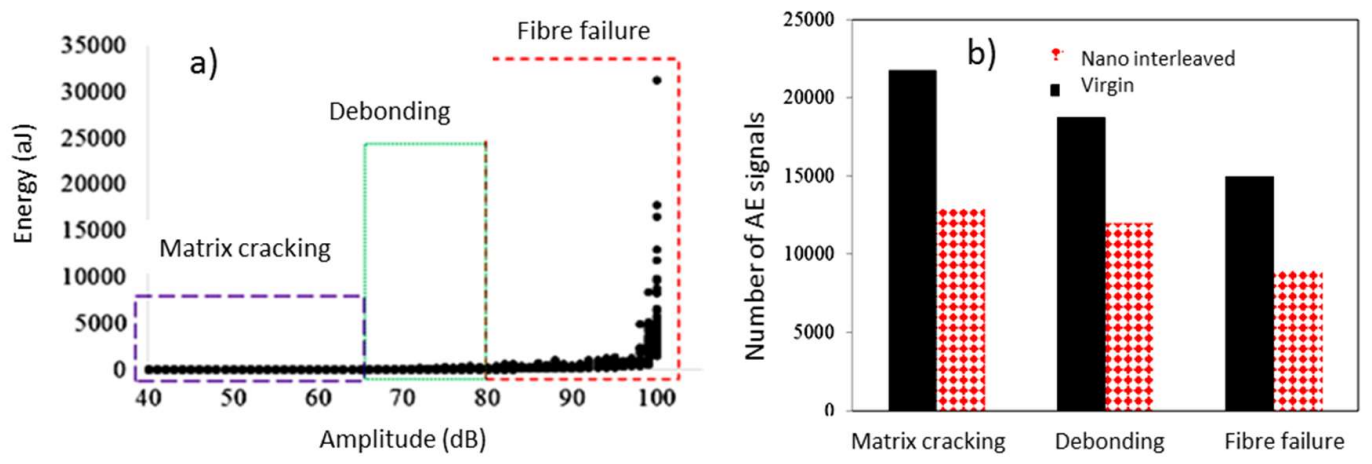

Figure 6. (a) Classification of the AE signals based on their Energy and Amplitude levels, (b) Number of AE signals associated with different failure mechanisms for the static loading.

a)

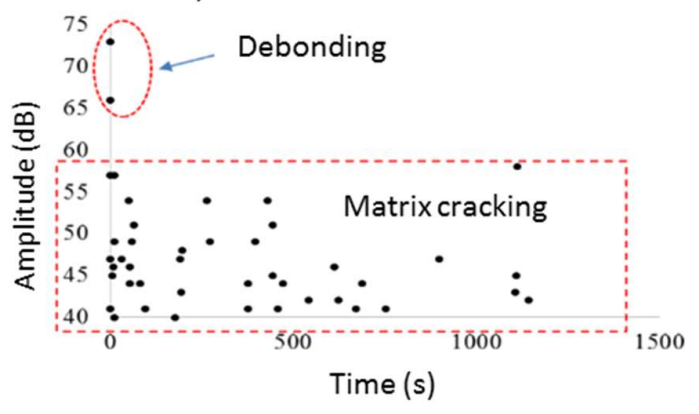

b)

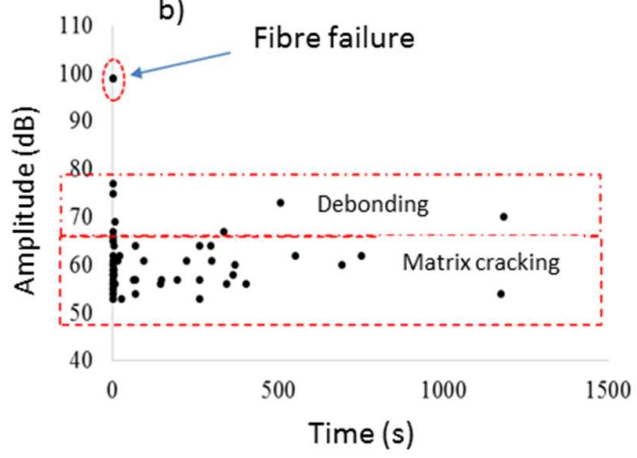

Figure 7. AE signals Amplitude distribution versus time for the fatigued samples (a) Virgin and (b) Nano-interleaved.

\section{Discussion}

As summarized in table 1, the nano-interleaved samples has shown, showed a $137 \%$ and a $124 \%$ increase of GIC and GR respectively, compared to pristine ones. The fracture toughness is increased at both crack initiation and propagation for the fatigue tests as illustrated in Figure 4.

Table 1. Fracture parameters obtained from mode I fracture tests.

\begin{tabular}{cccc}
\hline & \multicolumn{4}{c}{ GIC $(\mathrm{J} / \mathrm{m} 2)$ measured based on ASTM D5528 } \\
\hline Methods & NL & VIS & $5 \% / \max$ \\
\hline Virgin & $15 \pm 340$ & $20 \pm 385$ & $25 \pm 415$ \\
\hline Nano-interleaved & $30 \pm 790$ & $50 \pm 860$ & $60 \pm 1000$ \\
\hline
\end{tabular}

The obtained AE results are very helpful to understand the failure mechanisms contributed to increase the toughness of the specimens. The AE results indicate that matrix cracking damage has fewer numbers of AE signals in the nano-modified specimen compared with the virgin specimens. It means that the reason for the increase in the toughness of the modified specimens is not due to the thicker rich resin interface and it is mainly because of the PVDF nanofibers which were cured in appropriate curing temperature. 


\section{Conclusions}

In this paper the effect of interleaved PVDF nanofibers on mode I interlaminar properties and the appeared failure modes of woven carbon/epoxy laminates was investigated when subjected to static and fatigue loadings. DCB specimens were subjected to static and fatigue tests and the tests were monitored by acoustic emission technique. The mechanical results proved the ability of the PVDFnanofiberous mate to enhance fracture toughness in the initiation and propagation of delamination for both static and fatigue tests. The AE results showed that the number of interlaminar occurred failure modes diminished in the modified composite layers and there were more matrix cracking associated AE signals in the virgin sample compared with the nano-interleaved sample. It means that the reason for the increase in the toughness of the modified specimens is due to the change in the appeared damage mechanisms that require higher energy level to initiate and propagate. Finally, it can be concluded that the nano-interleaved samples can improve the delamination resistance of laminated composites under static and fatigue loadings.

\section{Author Contributions:}

Writing-original draft preparation, Sakineh. Fotouhi., Mohamad. Fotouhi. and Milad. Saeedifar., Conceptualization, Hamed. Saghafi., Cristiano. Fragassa.

Investigation, Sakineh. Fotouhi., Mohamad. Fotouhi.

Supervision, Giangiacomo. Minak.

Acknowledgments: Mohammad would like to tank Faculty of Environment and Technology at the University of the West of England for their travel funding support to build collaborative research with the University of Bologna.

Conflicts of Interest: The author(s) declared no potential conflicts of interest with respect to the research, authorship, and/or publication of this article.

\section{References}

1. Tsai, G.C.; Chen, J.W. Effect of stitching on mode I strain energy release rate. Compos Struct 2005,69,1-9.

2. Wong, D.W.Y.; Lin L.; McGrail, P.T.; et al. Improved fracture toughness of carbon Ebre/epoxy composite laminatesusing dissolvable thermoplastic Ebres. Compos Part A Appl Sci Manuf 2010,41,759-767.

3. Wang, CH.; Sidhu, K.; Yang, T.; et al. Interlayer self-healing and toughening of carbon fiber/epoxy composites using copolymer films. Compos Part A Appl Sci Manuf 2012, 43, 512-518.

4. Pavlovic, A.; Fragassa, C.; Disic, A. Comparative numerical and experimental study of projectile impact on reinforced concrete. Compos Part B: Engineering 2017,108, 122-130.

5. Tang, G.; Yan. Y; Chen, X.; et al. Dynamic damage and fracture mechanism of three-dimensional braided carbon fiber/epoxy resin composites. Mater Design, 2001,22,21-25.

6. Van, V.P.; Ballout, W.; Daoust, D.; et al. Influence of thermoplastic diffusion on morphology gradient and on delamination toughness of RTM-manufactured. Compos Part A Appl Sci Manuf 2015,72,175-183.

7. Sohn, M.S.; Hu, X.Z.; Kim, J.K.; et al. Impact damage characterization of carbon fiber/epoxy composites with multi-layer reinforcement. Compos Part B Eng 2000,31,681-691.

8. Yasaee, M.; Bond, I.P.; Trask, R.S.; et al. Mode I interfacial toughening through discontinuous interleaves for damage suppression and control. Compos Part A Appl Sci Manuf 2012,43,198-207.

9. Saghafi, H.; Zucchelli, A.; Palazzetti, R.; Minak, G. The effect of interleaved composite nanofibrous mats on delamination behavior of polymeric composite materials. Composite Structures 2014,109,41-47.

10. Brugo, T.M.; Minak, G.; Zucchelli, A.; Saghafi, H.; Fotouhi, M. An Investigation on the Fatigue based Delamination of Woven Carbon-epoxy Composite Laminates Reinforced with Polyamide Nanofibers. Procedia Engineering 2015,109,65-72.

11. Fotouhi, M.; Saghafi, H.; Brugo, T.; Minak, G.; Fragassa, C.; Zucchelli, A.; et al. Effect of PVDF nanofibers on the fracture behavior of composite laminates for high-speed woodworking machines. P I Mech Eng C-J Mec 2017,231,31-43.

12. Barre, S.; Benzeggagh, M.L.; On the use of acoustic emission to investigate damage mechanisms in glass fiber reinforced polypropylene. Compos Sci Tech 1994,52,369-376. 
13. Marec, A.; Thomas, J.H.; Guerjouma, E.R. Damage characterization of polymer-based composite materials: multivariable analysis and wavelet transform for clustering acoustic emission data. Mech Sys Sig Proc 2008,22,1441-1464.

14. Uenoya, T. Acoustic emission analysis on interfacial fracture of laminated fabric polymer matrix composites. J Acous Emiss 1995,13,95-102.

15. de Oliveira, R.; Marques, A.T.; Health monitoring of FRP using acoustic emission and artificial neural networks. Comput Struct 2008,86,367-373.

16. Fotouhi, M.; Pashmforoush, F.; Ahmadi, M.; et al. Monitoring of initiation and growth of delaminationin composite materials using acoustic emission under quasi-static 3-point bending test. J Reinf Plast Compos 2011,30,1481.

17. Pashmforoush, F.; Fotouhi, M.; Ahmadi, M. Acoustic emission-based damage classification of glass/polyester composites using harmony search k-means algorithm. J Reinf Plast Compos 2012,31, 671-680.

18. Saeedifar, M.; Fotouhi, M.; Ahmadi, M.; et al. Prediction of delamination growth in laminated composites using acoustic emission and cohesive zone modeling techniques. J Compos Struct 2015,124,120-127.

19. Fotouhi, M.; Ahmadi, M. Acoustic emission based study to characterize the initiation of mode I delamination in composite materials. J Thermoplast Compos Mater 2014,519-537.

20. Bohse, J. Acoustic emission characteristics of micro-failure processes in polymer blends and composites Compos Sci Technol 2000,60,1213-1226.

21. ASTM D5528. Standard test method for Mode I interlaminar fracture toughness of unidirectional fiberreinforced polymer matrix composites. Annual Book of ASTM Standards, 2007.

22. ASTM D6115. Standard Test Method for Mode I Fatigue Delamination Growth Onset of Unidirectional. Annual Book of ASTM Standards, 1997.

23. Ishbir, C.; Banks-Sills, L.; Fourman, V.; Eliasi, R. Delamination propagation in a multidirectional woven composite DCB specimen subjected to fatigue loading. Composites Part B: Engineering 2014,66,180-189.

24. Huang, M.; Jiang, L.; Liaw, P.K.; Brooks, Ch.R.; Seeley, R.; Klarstrom, D.L.; Using acoustic emission in fatigue and fracture materials research. Nondestruct Eval Overview 1998,50,11.

25. Barré, S.; Benzeggagh, M.L. On the use of acoustic emission to investigate damage mechanisms in glassfibre-reinforced poly-propylene. Compos Sci Technol 1994,52,369-376.

26. Benmedakhene, S.; Kenane, M.; Benzeggagh, M.L. Initiation and growth of delamination in glass/epoxy composites subjected to static and dynamic loading by acoustic emission monitoring. Compos Sci Technol 1999,59,201-208.

27. Guerjouma, R.E.; Baboux, J.C.; Ducret, D.; Godin, N.; Guy, P.; Huguet, S.; et al. Nondestructive evaluation of damage and failure of fiber reinforced polymer composites using ultrasonic waves and acoustic emission Adv Eng Mater 2001,3,601-608.

28. Woo, S.C.; Choi, N.S. Analysis of fracture process in single-edge-notched laminated composites based on the high amplitude acoustic emission events. Compos Sci Technol 2007 67,1451-1458.

29. Palazzetti, R.; Zucchelli,A.; Gualandi, C.; Focarete, M.L.; Donati, L.; Minak, G. Influence of electrospun Nylon 6,6 nanofibrous mats on the interlaminar properties of Gr-epoxy composite laminates. Compos Struct 2012,94,571-579.

30. Fotouhi ,M.; Ahmadi, M. Investigation of the mixed-mode delamination in polymer-matrix composites using acoustic emission technique. J Reinf Plastic Comp 2014,33,1767-1782.

31. Fotouhi, M.; Suwarta, P.; Jalalvand, M.; Czel, G.; Wisnom, M.R. Detection of fibre fracture and ply fragmentation in thin-ply UD carbon/glass hybrid laminates using acoustic emission. Compos A Appl Sci Manuf 2016, 10.1016/j.compositesa.2016.04.003. 